An Introduction to the Principles of Chemistry By Prof. L. H. Cragg and Prof. R. P. Graham. Pp. ix +740 . (London: George G. Harrap and Co., Ltd., 1954.) 35s. net.

THIS book, by two Canadian teachers, deals with what used to be called 'theoretical chemistry' and is not a text-book of inorganic chemistry. In the preface it is truly said that students from school beginning a course in a university are disheartened if their hardly won lknowledge, rudimentary and sometimes incorrect as it may be, is ignored and they are compelled to go through books containing much that they already know. The authors assume that the reader has such a knowledge, and they attempt to extend and correct it.

Among the topics dealt with are the discovery and classification of the elements, atomic and molecular structure, the kinetic theory, solutions, reaction velocity and equilibrium, electrolytes, energy changes, nuclear phenomena and trans-uranic elements, applications of nuclear science, and the use of less common elements in industry. The literary style is excellent, and the book is well illustrated. Care is taken to explain all difficult points (the section on the kinetic theory of gases is notably good in this respect), and there are good exercises and hints for further reading at the ends of the chapters.

In many places the authors attempt to inspire the young reader with a real love of science and make it clear that much remains to be done in known fields, not to mention much that may yet be quite unknown. What may be called the research spirit enlivens the whole text. This is a notably good book which every teacher of chemistry ought to see. Although very modern in content and inspiration, it frequently uses the historical approach and something is said of the personalities whose work has built up the science of chemistry. Most young students are attracted by such a treatment, as the authors well know. It can win new workers in the field, and the book openly encourages its readers to join the ranks of the discoverers. The book is very attractively produced, and its price is moderate.

\section{Experimental Inorganic Chemistry}

By Dr. W. G. Palmer. Pp. $\mathrm{xx}+578$. (Cambridge : At the University Press, 1954.) 50s. net.

COURSES in practical inorganic chemistry have 4 always been a problem for the teacher. Most students have done parts at school, and the severe discipline called for in quantitative inorganic analysis is apt to be irksome as compared with the rather untidy progress through a course of organic preparations.

Dr. W. G. Palmer has had the ingenious idea of combining the analysis with the preparative work, and of introducing the preparation of substances not too familiar to the students but of undoubted interest and importance. The first hundred or so pages give a concise survey of modern theory in inorganic chemistry, and the book then goes through the preparations and analyses in the order of the elements in the periodic table. A compound is first prepared and then quantitatively analysed. It is certain that this plan will enliven the subject, make it more intelligible and interesting, and give the student $a_{0}$ better appreciation of inorganic chemistry as a whole.

At the end of each section there is a short list of literature references, which are intended to be read. The theory is extended in the introduction to each group, so that the book provides a concise text-book of inorganic chemistry as well as a practical course. Many of the exercises could be done at school, and all are suitable for university courses. Dr. Palmer's book can be strongly recommended to all concerned with teaching practical inorganic chemistry, and every teacher of the subject in school or university should have a copy.

\section{Sunspot and Geomagnetic-Storm Data derived from Greenwich Observations 1874-1954}

Compiled under the direction of Sir Harold Spencer Jones. Pp. viii + 106. (London: H.M.S.O., 1955.) 25s. net.

GOR the past eighty years the annual volumes of I the "Greenwich Magnetic and Meteorological Observations" and "Greenwich Photoheliographic Results" have served to tabulate data on geomagnetic storms and measures of sunspot areas and positions. This wealth of material has now been collected in $\mathbf{a}$ single volume which includes catalogues of the larger sunspots and of great and small geomagnetic storms, and tables of areas of sunspots and facula with detailed information on the latitude distribution of the sunspots.

A feature which will be welcomed by many workers is the adoption of the calendar month for the mean areas of sunspots and faculæ; this will go far to justify the hope of Sir Harold Spencer Jones that "this compilation .... will be useful to those investigating solar-terrestrial relationships". Each section contains explanatory notes and references to published papers; some diagrams have also been included, among which it is interesting to find Maunder's 'butterfly' diagram, which has been brought up to date and now contains more than seven complete cycles.

\section{Thermionic Valves 1904-1954}

The First Fifty Years. Pp. iii +70. (London : Institution of Electrical Engineers, 1955.) $9 s$.; or 48 . to members.

$\triangle$ DETAILED account of the celebrations, held A in November 1954, of the jubilee of the thermionic valve has already been published in Nature (174, 1076 ; 1954). As a record of the proceedings which took place on that occasion, the Institution of Electrical Engineers has published a most attractive book entitled "Thermionic Valves 1904-1954: The First Fifty Years". The frontispiece is a photograph of the original Fleming diode; and this is followed by an appreciation of Sir Ambrose Fleming and Dr. Lee de Forest by Captain C. F. Booth, together with a copy of both the provisional and complete specifications of British Patent No. 24850 : 1904, applied for by Fleming on November 16, 1904 .

The next thirty pages of the book comprise the full texts of the opening address of the Marquess of Salisbury, and the three lectures given by Prof. G. W. O. Howe, Sir Edward Appleton and Dr. J. Thomson, on the occasion of the meeting at the Institution last November. The last two lectures are well illustrated by some excellent diagrams and photographs of typical valves and circuit arrangements. The book is completed by a catalogue of 242 types of thermionic valve, with nearly fifty photographs, representative of experiment and production over the past fifty years.

All those interested in the history of the thermionic valve, and the part it has played in the development of telecommunications and electronics, will welcome this publication.
R. L. S.-R. 